\title{
Validation of a Chinese Version of the Self-Efficacy for Managing Chronic Disease 6-Item Scale in Patients with Hypertension in Primary Care
}

\author{
Huanhuan Hu, ${ }^{1}$ Gang Li, ${ }^{2}$ and Takashi Arao ${ }^{3}$ \\ ${ }^{1}$ Lab of Exercise Epidemiology, Graduate School of Sport Sciences, Waseda University, Mikajima, Saitama 3591192, Japan \\ ${ }^{2}$ Institute of Chronic Diseases Control and Prevention, Beijing Center for Diseases Control and Prevention, Beijing 100013, China \\ ${ }^{3}$ Lab of Exercise Epidemiology, Faculty of Sport Sciences, Waseda University, 2-579-15 Mikajima, Tokorozawa, Saitama 359-1192, Japan \\ Correspondence should be addressed to Takashi Arao; tarao@waseda.jp
}

Received 18 March 2013; Accepted 12 April 2013

Academic Editors: C. M. Buchalla, C. Rissel, A. Slep, and A. Zaborskis

Copyright (c) 2013 Huanhuan Hu et al. This is an open access article distributed under the Creative Commons Attribution License, which permits unrestricted use, distribution, and reproduction in any medium, provided the original work is properly cited.

\begin{abstract}
The aim of this study was to validate a Chinese version of the Self-Efficacy for Managing Chronic Disease 6-Item Scale (SES6C). In 2012, a cross-sectional study was conducted in a community clinic, in Beijing, China. A total of 262 hypertension patients participated in this study. Concurrent validity was validated by Pearson's correlations between the SES6C and Hospital Anxiety and Depression Scale (HADS). Intraclass correlation coefficients (ICC) were performed to evaluate test-retest reliability of the scale. Related factors of self-efficacy were explored in linear regression models. The results of our study display acceptable psychometric properties: the scale was two-dimensional, reproducible (ICC $=0.78 ; 95 \% \mathrm{CI}, 0.70-0.84$ ), and the reliability was good (Cronbach's alpha $=0.88)$. Significant $(r=-0.30 ; P<0.001)$ correlation was found between the level of self-efficacy and the level of psychological distress. In multivariable analysis, the factors significantly associated with self-efficacy were regular exercise $(\beta=0.659, P<0.01)$, HADS total score $(\beta=-0.076, P<0.001)$ and health status $(\beta=-0.530, P<0.001)$. The study provides evidence that the SES6C is acceptable, valid and repeatable for hypertension patients.
\end{abstract}

\section{Introduction}

Hypertension management requires the individual to perform varying forms of self-care behaviors, according to the recommendations of the Joint National Committee on Prevention, Detection, Evaluation, and Treatment of High Blood Pressure (JNC7) [1]. Self-efficacy, a widely used psychological concept, has been recognized as an essential prerequisite of effective self-care of chronic disease [2-4]. Several studies have underlined the association between self-efficacy and chronic disease self-care among hypertension, diabetes, and arthritis [5-7]. In a study by Warren-Findlow and colleagues [8], hypertension self-efficacy is strongly associated with adherence to five of the six JNC7 recommended self-care behaviors. In China, the prevalence of hypertension in adults may reach to $25 \%$ in recent years according to reports from various provinces [9-11]. However, low prevalence rate of selfcare engagement among hypertension patients was reported in China [12].

Measuring the self-efficacy for self-care behaviors in hypertension patients is an important step towards improving hypertension control in individual or population level. The information gained from measurement of self-efficacy can help physicians or public health professionals to identify low self-efficacy patients and implement suitable interventions. Thus, there is a need for a measure which could be used as a screening method both at research and clinical practices. Sorts of self-efficacy instruments have been developed and tested throughout the last two decades [13-15]. However, to date, no instrument has been standardized for measuring self-efficacy in hypertension patients. The choice of specific 
measure also depends on the intended use of the information, patients' acceptance, and convenience of the tool [16].

The Self-Efficacy for Managing Chronic Disease 6-Item Scale is less burdensome for patients and can effectively be used in research and clinical practices. This short instrument was developed and validated by the Stanford Patient Education Resource Center [17]. It encompasses several domains that are common across many chronic diseases including symptom control, role function, emotional functioning, and communicating with physicians. The German translation of this measure has been demonstrated to be a reliable and valid measure [18].

Until now, there is no Chinese version of the Self-Efficacy for Managing Chronic Disease 6-Item Scale (SES6C). The main objective of this study was to evaluate the validity and reliability of a Chinese version of the SES6C in patients with hypertension. The secondary objectives were to explore factors associated with self-efficacy measured with the SES6C.

\section{Methods}

2.1. Design and Setting. In 2012, an observational crosssectional study was conducted to assess the reliability and validity of SES6C in a hypertension population. A questionnaire survey was undertaken in a local community health clinic in Beijing, China.

2.2. Participants. We recruited subjects for this study through the community health clinic. A total of 890 hypertension patients were registered in the health clinic. Physicians screened the registered patients for eligibility for the study, and 456 patients who met the eligible criteria were invited to participate in this study. Eligible participants were aged 35 years and over and had been diagnosed with hypertension for at least 12 months. Participants who cannot communicate effectively with the study personnel or provide informed consent were excluded.

Two weeks after the first interview, half of the patients conveniently selected from the subjects who had finished the first questionnaire were interviewed for a second time by the same interviewers. All the measures were orally administrated by trained interviewers at the study site and followed an interview guide. The duration of the interviews ranged from 15 to $20 \mathrm{~min}$.

Approval to conduct the study was granted from the Ethical Review Board in Waseda University. Informed consent was obtained from all the participants prior to data collection. Participants were informed that they could stop the interview at any time.

2.3. Translation of the SES6C. The original version of the SES6C is free to use without permission. A forward and back translation was carried out to confirm accuracy. This is a minimum requirement for the cross-cultural adaptation of established scales [19]. The forward translation (English to Chinese) was undertaken by the first author of this paper. Translations were reviewed and discussed with the second author and one public health professional in meetings. A revised version was translated back by a $\mathrm{Ph}$. D. candidate in Nagoya University. All were fluent in English and Chinese. The original and the back-translated English versions were compared and inconsistencies were resolved through consensus meetings. The Chinese version was finalized when there was no dispute or new suggestion.

\section{Measurements}

3.1. Self-Efficacy for Managing Chronic Disease 6-Item Scale. The SES6C is a measure of how confident patients with chronic disease are in doing certain activities. The measure consists of 6 items that are rated on a 10-point scale ranging from "not at all confident" (1) to "totally confident" (10). The high internal consistency reliability of 0.91 and moderate correlation ( $r=0.58)$ with General Self-efficacy Scale indicates that its validity and reliability are acceptable $[17,20]$. The scale is interpreted by calculating a mean score over at least four of the six items thus allowing a maximum of two missing item responses. Higher number indicates higher selfefficacy.

The subjects in our study were mainly from rural areas and had a low literacy rate. In order to make comprehension easier and improve the measurement accuracy, an interview guide for this scale was developed by the first author.

3.2. Hospital Anxiety and Depression Scale (HADS). A large body of evidence shows that concept of self efficacy has a general role on mental health [21-23]. Tahmassian and colleagues reported that there is a significant and negative relationship between self-efficacy and depression $(r=-0.42)$ and anxiety $(r=-0.46)$ [24]. To investigate the concurrent validity of the SES6C, the validated Chinese version of HADS $[25,26]$ was used as an external criterion. The HADS is widely used as a screening measure for both dimensional and categorical aspects of anxiety and depression [27]. A greater score of the HADS represents a higher level of psychological distress.

In addition to previously mentioned self-efficacy, anxiety, and depression measures, demographic information was also collected in the questionnaire regarding respondents' age, gender, education level, marital status $(1=$ married, 2 = widowed, and $3=$ divorced/separated and unmarried), smoking status $(1=$ yes, $0=$ no), perceived health status $(1$ $=$ very good, 2 = good, $3=$ fair, $4=$ poor, and $5=$ very poor), regular exercise $(1=$ yes, $0=$ no), and duration of hypertension.

3.3. Data Management and Statistical Analyses. Data were double-entered and cross-checked using Epi Info version 6 statistical software. Descriptive statistics such as means, standard deviations, medians, percentages, and range were used when appropriate. Exploratory factor analysis was performed on the items to test the SES6C underlying dimensions. Principal component analysis with varimax rotation was performed to extract the factors. Factors with an eigenvalue $\geq 1.0$ were kept as part of the factor structure. Scale internal consistency 
reliability was determined by calculating Cronbach's alpha. Internal reliability is acceptable if the Cronbach's alpha coefficient is greater than 0.70 [28]. Test-retest reliability was evaluated using the intraclass correlation coefficient (ICC), and an ICC value of 0.40 represents moderate, 0.60 good, and 0.80 high agreement [29]. Concurrent validity was established by Pearson's correlations between the 6-Item SES6C and HADS. A moderate to high correlation between the relevant dimensions was deemed acceptable $(r \geq 0.3)$ [30].

An explanatory analysis was performed to study whether the demographic and clinical variables were associated with self-efficacy according to the SES6C. The factors explored were age, gender, smoking status, education level, marital status, regular exercise, perceived health status, duration of hypertension, and psychological distress (HADS total score). Linear regression models were used. All factors were studied in univariable and multivariable analyses. Statistical analyses of the study were conducted by SPSS 19.0 for Windows (SPSS, Inc., Chicago, USA), and the significance level was set at 0.05 .

\section{Results}

4.1. Sample Characteristics. In total, 299/456 hypertension patients (65.6\%) accepted the invitation to this study. Among these participants, 262 of them $(87.6 \%)$ completed the first questionnaire. Of the 140 patients conveniently selected for the second questionnaire to assess test-retest reliability, 127 of them provided complete answers.

The characteristics of the study sample are shown in Table 1. Of the 262 respondents, $72.1 \%$ were female and $74.8 \%$ had a lower educational level ( $\leq 6$ years). Mean age was $63.4 \pm 9.7$ years (range: $35-83$ years). No significant differences based on age, gender, education level, marital status, smoking status, or psychological distress were found between the participants who completed the questionnaire for a second time and those who did not. The participants who were retested had a longer duration of hypertension $(t=$ 2.38; $P<0.05)$.

4.2. Construct Structure. Prior to performing factor analysis, the suitability of the data for such analysis was assessed using the Kaiser-Meyer-Olkin (KMO) method and Bartlett's test of sphericity. The KMO value of 0.80 and the statistical significance of Bartlett's test of sphericity $\left(\chi^{2}=941.04\right.$; $P<0.001)$ supported that the data were appropriate for exploratory factor analysis. Our factor analysis for the SES6C resulted in a two-factor solution (factor 1, 63.0\%; factor 2, $16.8 \%$ ) that accounted for $79.8 \%$ of the variance (Table 2 ).

4.3. Concurrent Validity. There were significant correlations between the SES6C and the HADS total score $(r=-0.30 ; P<$ $0.001)$, HADS depression subscale $(r=-0.23 ; P<0.001)$, and HADS anxiety subscale $(r=-0.29 ; P<0.001)$ (Table 3$)$. The negative correlation coefficients indicated the greater the level of self-efficacy rated using the SES6C the lower the level of anxiety and depression rated using HDAS.
TABLE 1: Characteristics of the sample.

\begin{tabular}{|c|c|c|c|}
\hline & $\begin{array}{c}\text { Total } \\
N=262 \\
(\%)\end{array}$ & $\begin{array}{c}\text { Test } \\
N=135 \\
(\%)\end{array}$ & $\begin{array}{c}\text { Retest } \\
N=127 \\
(\%)\end{array}$ \\
\hline \multicolumn{4}{|l|}{ Age } \\
\hline $35-64$ & $138(52.6)$ & $73(54.1)$ & $65(51.2)$ \\
\hline $65-83$ & $124(47.3)$ & $62(45.9)$ & $62(48.8)$ \\
\hline Mean (SD) & $63.4( \pm 9.7)$ & $\begin{array}{c}62.9 \\
( \pm 10.5)\end{array}$ & $64.0( \pm 8.7)$ \\
\hline \multicolumn{4}{|l|}{ Gender } \\
\hline Male & $73(27.9)$ & $46(34.1)$ & $27(21.3)$ \\
\hline Female & $189(72.1)$ & $89(65.9)$ & $100(78.7)$ \\
\hline \multicolumn{4}{|l|}{ Level of education } \\
\hline$\leq 6$ years & $196(74.8)$ & $94(69.6)$ & $102(80.3)$ \\
\hline$>6$ years & $66(25.2)$ & $41(30.4)$ & $25(19.7)$ \\
\hline \multicolumn{4}{|l|}{ Marital status } \\
\hline Married & $228(87.0)$ & $119(88.1)$ & $109(85.8)$ \\
\hline Others & $34(13.0)$ & 16 (11.9) & $18(14.2)$ \\
\hline \multicolumn{4}{|l|}{ Smoking status } \\
\hline Yes & $56(21.4)$ & $30(22.2)$ & $26(20.5)$ \\
\hline No & $206(78.6)$ & $105(77.8)$ & $101(79.5)$ \\
\hline $\begin{array}{l}\text { Years of hypertension, } \\
\text { mean (SD) }\end{array}$ & $8.6( \pm 7.2)$ & $7.5( \pm 6.4)$ & $9.6( \pm 7.8)^{*}$ \\
\hline HADS, mean (SD) & $8.9( \pm 6.4)$ & $8.6( \pm 6.1)$ & $9.1( \pm 6.7)$ \\
\hline $\begin{array}{l}\text { HADS depression, } \\
\text { mean (SD) }\end{array}$ & $4.5( \pm 3.5)$ & $4.3( \pm 3.3)$ & $4.6( \pm 3.6)$ \\
\hline $\begin{array}{l}\text { HADS anxiety, } \\
\text { mean (SD) }\end{array}$ & $4.4( \pm 3.8)$ & $4.3( \pm 3.6)$ & $4.5( \pm 4.0)$ \\
\hline
\end{tabular}

${ }^{*}$ Significant at the 0.05 level.

4.4. Internal Consistency and Test-Retest Reliability. Cronbach's alpha for the SES6C was 0.88 and the split-half was 0.80 , representing an acceptable internal consistency. The item-total correlations ranged from 0.61 to 0.77 (Table 2). Retests for reliability were completed by 127 patients who completed the first questionnaires. The ICC was 0.78 (95\% CI, 0.70-0.84) for the SES6C mean score. The ICC of individual item ranged from 0.68 to 0.76 . All of these ICCs are in the good to excellent reliability range.

4.5. Related Factors of Self-Efficacy. In univariable analysis, a statistically significant increase in self-efficacy was observed with regular exercise, lower HADS total score, and better health status. After adjustment for all factors of self-efficacy, the factors significantly associated with self-efficacy were still regular exercise $(\beta=0.659, P<0.01)$, HADS total score $(\beta=-0.076, P<0.001)$, and health status $(\beta=-0.530$, $P<0.001)$.

\section{Discussion}

This study validates the SES6C for use in the field of hypertension. The results of this study showed acceptable validity (two-dimensional structure, concurrent validity: 
TABLE 2: Corrected item-to-total correlation and factors loading of the SES6C.

\begin{tabular}{|c|c|c|c|c|}
\hline Items & Mean (SD) & $\begin{array}{l}\text { Corrected } \\
\text { item-total } \\
\text { correlation }\end{array}$ & Factor 1 & Factor 2 \\
\hline $\begin{array}{l}\text { (1) How confident are you that you can keep the fatigue caused by your disease } \\
\text { from interfering with the things you want to do? }\end{array}$ & $6.5( \pm 2.7)$ & 0.71 & 0.824 & 0.240 \\
\hline $\begin{array}{l}\text { (2) How confident are you that you can keep the physical discomfort or pain of your } \\
\text { disease from interfering with the things you want to do? }\end{array}$ & $6.3( \pm 2.7)$ & 0.72 & 0.891 & 0.154 \\
\hline $\begin{array}{l}\text { (3) How confident are you that you can keep the emotional distress caused by your } \\
\text { disease from interfering with the things you want to do? }\end{array}$ & $6.5( \pm 2.7)$ & 0.71 & 0.809 & 0.259 \\
\hline $\begin{array}{l}\text { (4) How confident are you that you can keep any other symptoms or health } \\
\text { problems you have from interfering with the things you want to do? }\end{array}$ & $6.6( \pm 2.6)$ & 0.77 & 0.782 & 0.368 \\
\hline $\begin{array}{l}\text { (5) How confident are you that you can do the different tasks and activities needed } \\
\text { to manage your health condition so as to reduce that you need to see a doctor? }\end{array}$ & $6.7( \pm 2.6)$ & 0.61 & 0.243 & 0.911 \\
\hline $\begin{array}{l}\text { (6) How confident are you that you can do things other than just taking medication } \\
\text { to reduce how much your illness affects your everyday life? }\end{array}$ & $6.8( \pm 2.5)$ & 0.63 & 0.272 & 0.897 \\
\hline
\end{tabular}

TABLE 3: Correlations between self-efficacy and psychological distress.

\begin{tabular}{lcccc}
\hline & Self-efficacy & Depression of HADS & Anxiety of HADS & Total score of HADS \\
\hline Self-efficacy & 1 & $-0.23^{*}$ & $-0.29^{*}$ & $-0.30^{*}$ \\
Depression of HADS & & 1 & $0.54^{*}$ & $0.86^{*}$ \\
Anxiety of HADS & & & 1 & $0.90^{*}$ \\
Total score of HADS & & & 1 \\
\hline
\end{tabular}

* Significant at the 0.001 level.

$r=-0.30, P<0.001$ ) and high reliability (Cronbach's alpha $=0.88, \mathrm{ICC}=0.78 ; 95 \% \mathrm{CI}, 0.70-0.84)$ of the SES6C.

In our sample, 456 registered patients were invited through telephone, 262 of them completed the interview. The response rate for this study was a little lower than expected, and then some characteristics of the responders might be different from the rest of the patients.

Freund and colleagues [18] reported a one-dimensional structure derived from a sample of 244 participants, most of whom were suffering from at least two cooccurring chronic conditions. In our sample, the results of factor analysis showed that all items split into two factors. Although the potential reasons for the difference in the result are unclear, one possible explanation might be due to the context difference between item 5, 6, and other 4 items. Item 5 and 6 give more emphasis to behavior attitude; however, the other 4 items emphasize more on psychological attitude. Another potential explanation is that the findings of factor analysis may be sample specific. Further study is needed to validate the structure of the SES6C.

A growing body of evidence suggests that self-efficacy is an important correlate of psychological well-being [22-24], though a causal relation requires further clarification. In our study, the concurrent validity of the SES6C was examined in relation to the HADS. The negative correlations between self-efficacy and depression and anxiety found in this study are consistent with the results in previous studies [22-24], suggesting acceptable concurrent validity and potential use as a research tool.

Self-efficacy has been recognized as a major predictor of self-care behavior for chronic disease management. In a longitudinal study of older women with heart disease, self-efficacy predicted the older women's adopting healthy diet and regular exercise [31]. Our exploratory analysis of factors of self-efficacy indicated that those with higher selfefficacy reported better health status, regular exercise, and lower psychological distress. These findings are consistent with previous studies $[31,32]$. Self-efficacy has been identified as a likely factor in the exercise behaviors of older men and women $[33,34]$. In our study, about half of the participants were aged 65 and over. This may partly explain the significant association between self-efficacy and regular exercise in this study. Another possible explanation might be that selfefficacy is behavior specific [31]. Patients might feel very efficacious about getting adequate exercise. Our results also provide further evidence that self-efficacy as a modifiable personal factor should be included either as intervention elements or evaluation measures in the future hypertension control program.

5.1. Limitations. Selection bias may have occurred. The subjects who agreed to participate in this study could be different from those who did not participate. The sample contained more women than men in our study. This uneven sampling 
is not ideal for a psychometric study. The measures were administrated to participants by interviewers. People may like to report desirable results. However, given the age and level of literacy among the sample, there was little alternative.

\section{Conclusions}

The findings from this validation study indicate that the SES6C is a reliable and valid measure at research and clinical practices. This economic, less burdensome instrument can be used in future hypertension control program for Chinese patients.

\section{Conflict of Interests}

The authors declare no conflict of interests.

\section{Acknowledgments}

The authors thank all the participating patients for their commitment. Special thanks are addressed to field investigators for their invaluable help in the project. This research was supported by grant of GCOE in Waseda University.

\section{References}

[1] A. V. Chobanian, G. L. Bakris, H. R. Black et al., "The seventh report of the Joint National Committee on Prevention, Detection, Evaluation, and Treatment of High Blood Pressure: the JNC 7 report," The Journal of the American Medical Association, vol. 289, no. 19, pp. 2560-2572, 2003.

[2] T. Bodenheimer, K. Lorig, H. Holman, and K. Grumbach, "Patient self-management of chronic disease in primary care," The Journal of the American Medical Association, vol. 288, no. 19, pp. 2469-2475, 2002.

[3] S. Du and C. Yuan, "Evaluation of patient self-management outcomes in health care: a systematic review," International Nursing Review, vol. 57, no. 2, pp. 159-167, 2010.

[4] H. Leventhal, J. Weinman, E. A. Leventhal, and L. A. Phillips, "Health psychology: the search for pathways between behavior and health," Annual Review of Psychology, vol. 59, pp. 477-505, 2008.

[5] R. Marks, J. P. Allegrante, and K. Lorig, "A review and synthesis of research evidence for self-efficacy-enhancing interventions for reducing chronic disability: implications for health education practice (part II)," Health Promotion Practice, vol. 6, no. 2, pp. 148-156, 2005.

[6] K. Farrell, M. N. Wicks, and J. C. Martin, "Chronic disease selfmanagement improved with enhanced self-efficacy," Clinical Nursing Research, vol. 13, no. 4, pp. 289-308, 2004.

[7] H. B. Bosworth and E. Z. Oddone, "A model of psychosocial and cultural antecedents of blood pressure control," Journal of the National Medical Association, vol. 94, no. 4, pp. 236-248, 2002.

[8] J. Warren-Findlow, R. B. Seymour, and L. R. Brunner Huber, "The association between self-efficacy and hypertension selfcare activities among African American adults," The Journal of Community Health, vol. 37, no. 1, pp. 15-24, 2012.

[9] S. S. Hu, L. Z. Kong, R. L. Gao et al., "Outline of the report on cardiovascular disease in China, 2010," Biomedical and Environmental Sciences, vol. 25, no. 3, pp. 251-256, 2012.
[10] W. J. Ma, J. L. Tang, Y. H. Zhang et al., "Hypertension prevalence, awareness, treatment, control, and associated factors in adults in Southern China," American Journal of Hypertension, vol. 25, no. 5, pp. 590-596, 2012.

[11] Y. F. Wu, R. Huxley, L. M. Li et al., "Prevalence, awareness, treatment, and control of hypertension in China: data from the China National Nutrition and Health Survey 2002," Circulation, vol. 118, no. 25, pp. 2679-2686, 2008.

[12] Z. Q. Sun, L. Q. Zheng, R. Detrano et al., "Incidence and predictors of hypertension among rural Chinese adults: results from Liaoning Province," The Annals of Family Medicine, vol. 8, no. 1, pp. 19-24, 2010.

[13] K. R. Lorig, R. L. Chastain, E. Ung, S. Shoor, and H. R. Holman, "Development and evaluation of a scale to measure perceived self-efficacy in people with arthritis," Arthritis \& Rheumatism, vol. 32, no. 1, pp. 37-44, 1989.

[14] J. V. Bijl, A. V. Poelgeest-Eeltink, and L. Shortridge-Baggett, "The psychometric properties of the diabetes management selfefficacy scale for patients with type 2 diabetes mellitus," Journal of Advanced Nursing, vol. 30, no. 2, pp. 352-359, 1999.

[15] A. R. Webel and J. Okonsky, "Psychometric properties of a symptom management self-efficacy scale for women living with HIV/AIDS," Journal of Pain and Symptom Management, vol. 41, no. 3, pp. 549-557, 2011.

[16] K. C. Farmer, "Methods for measuring and monitoring medication regimen adherence in clinical trials and clinical practice," Clinical Therapeutics, vol. 21, no. 6, pp. 1074-1090, 1999.

[17] Stanford Patient Education Research Center, Self-Efficacy for Managing Chronic Disease 6-item Scale, 2012, http://patienteducation.stanford.edu/research/secd6.html.

[18] T. Freund, J. Gensichen, K. Goetz et al., "Evaluating self-efficacy for managing chronic disease: psychometric properties of the six-item self-efficacy scale in Germany," Journal of Evaluation in Clinical Practice, vol. 19, no. 1, pp. 39-43, 2013.

[19] R. W. Brislin, "Back-translation for cross-cultural research," Journal of Cross-Cultural Psychology, vol. 1, no. 3, pp. 185-216, 1970.

[20] K. R. Lorig, D. S. Sobel, P. L. Ritter, D. Laurent, and M. Hobbs, "Effect of a self-management program on patients with chronic disease," Effective Clinical Practice, vol. 4, no. 6, pp. 256-262, 2001.

[21] Y. Chang, P. C. Wang, H. H. Li, and Y. C. Liu, "Relations among depression, self-efficacy and optimism in a sample of nurses in Taiwan," Journal of Nursing Management, vol. 19, no. 6, pp. 769776, 2011.

[22] P. K. Maciejewski, H. G. Prigerson, and C. M. Mazure, "Self-efficacy as a mediator between stressful life events and depressive symptoms. Differences based on history of prior depression," British Journal of Psychiatry, vol. 176, pp. 373-378, 2000.

[23] P. Muris, "Relationships between self-efficacy and symptoms of anxiety disorders and depression in a normal adolescent sample," Personality and Individual Differences, vol. 32, no. 2, pp. 337-348, 2002.

[24] K. Tahmassian and N. J. Moghadam, "Relationship between self-efficacy and symptoms of anxiety, depression, worry and social avoidance in a normal sample of students," Iranian Journal of Psychiatry and Behavioral Sciences, vol. 5, no. 2, pp. 91-98, 2011.

[25] W. Wang, S. Y. Chair, D. R. Thompson, and S. F. Twinn, "A psychometric evaluation of the Chinese version of the hospital 
anxiety and depression scale in patients with coronary heart disease," Journal of Clinical Nursing, vol. 18, no. 17, pp. 24362443, 2009.

[26] C. M. Leung, Y. K. Wing, P. K. Kwong, A. Lo, and K. Shum, "Validation of the Chinese-Cantonese version of the hospital anxiety and depression scale and comparison with the Hamilton rating scale of depression," Acta Psychiatrica Scandinavica, vol. 100, no. 6, pp. 456-461, 1999.

[27] I. Bjelland, A. A. Dahl, T. T. Haug, and D. Neckelmann, “The validity of the hospital anxiety and depression scale. An updated literature review," Journal of Psychosomatic Research, vol. 52, no. 2, pp. 69-77, 2002.

[28] J. M. Bland and D. G. Altman, "Cronbach's alpha," British Medical Journal, vol. 314, no. 7080, p. 572, 1997.

[29] K. A. Wilson, A. J. Dowling, M. Abdolell, and I. F. Tannock, "Perception of quality of life by patients, partners and treating physicians," Quality of Life Research, vol. 9, no. 9, pp. 1041-1052, 2000.

[30] W. Wang, D. R. Thompson, S. Y. Chair, and D. L. Hare, "A psychometric evaluation of a Chinese version of the Cardiac depression scale," Journal of Psychosomatic Research, vol. 65, no. 2, pp. 123-129, 2008.

[31] N. M. Clark and J. A. Dodge, "Exploring self-efficacy as a predictor of disease management," Health Education \& Behavior, vol. 26, no. 1, pp. 72-89, 1999.

[32] M. J. Cross, L. M. March, H. M. Lapsley, E. Byrne, and P. M. Brooks, "Patient self-efficacy and health locus of control: relationships with health status and arthritis-related expenditure," Rheumatology, vol. 45, no. 1, pp. 92-96, 2006.

[33] D. L. Gill, B. C. Kelley, K. Williams, and J. J. Martin, “The relationship of self-efficacy and perceived well-being to physical activity and stair climbing in older adults," Research Quarterly for Exercise and Sport, vol. 65, no. 4, pp. 367-371, 1994.

[34] D. Grembowski, D. Patrick, P. Diehr et al., "Self-efficacy and health behavior among older adults," Journal of Health and Social Behavior, vol. 34, no. 2, pp. 89-104, 1993. 


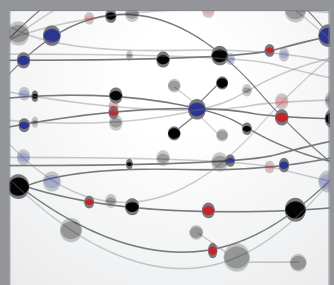

The Scientific World Journal
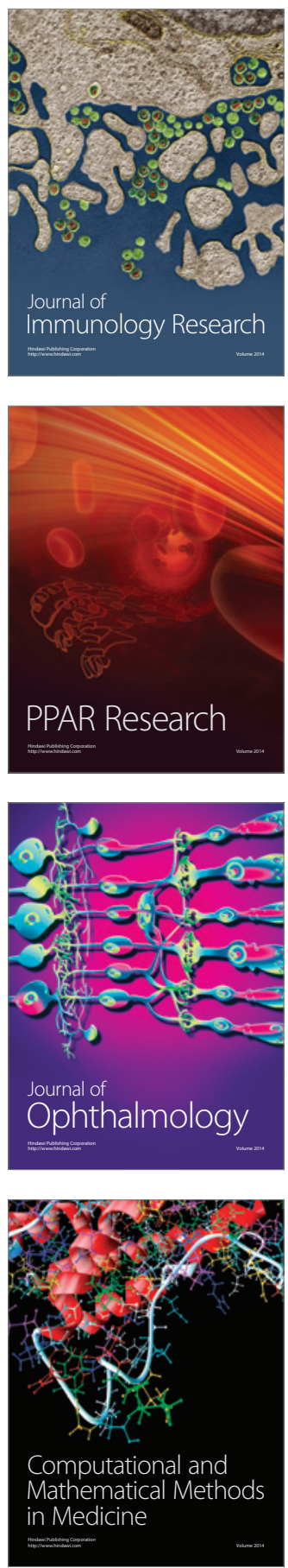

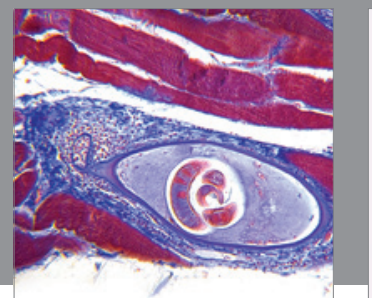

Gastroenterology

Research and Practice
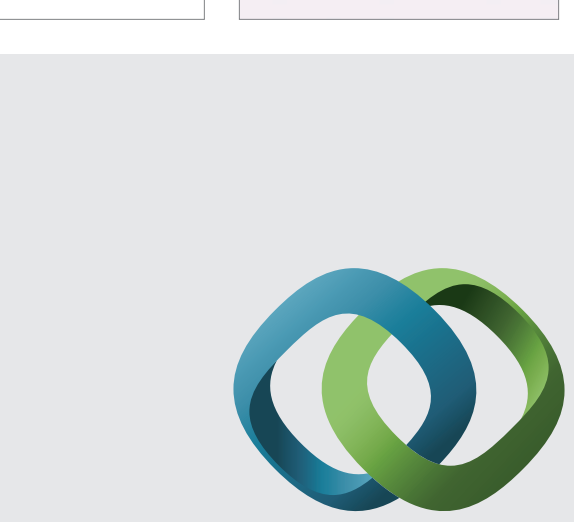

\section{Hindawi}

Submit your manuscripts at

http://www.hindawi.com
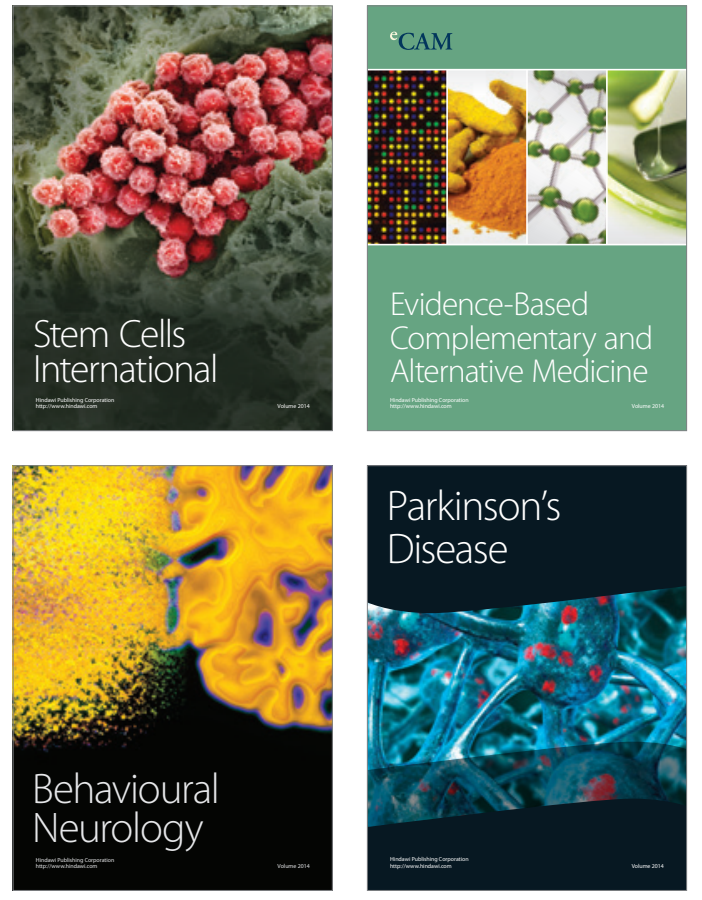
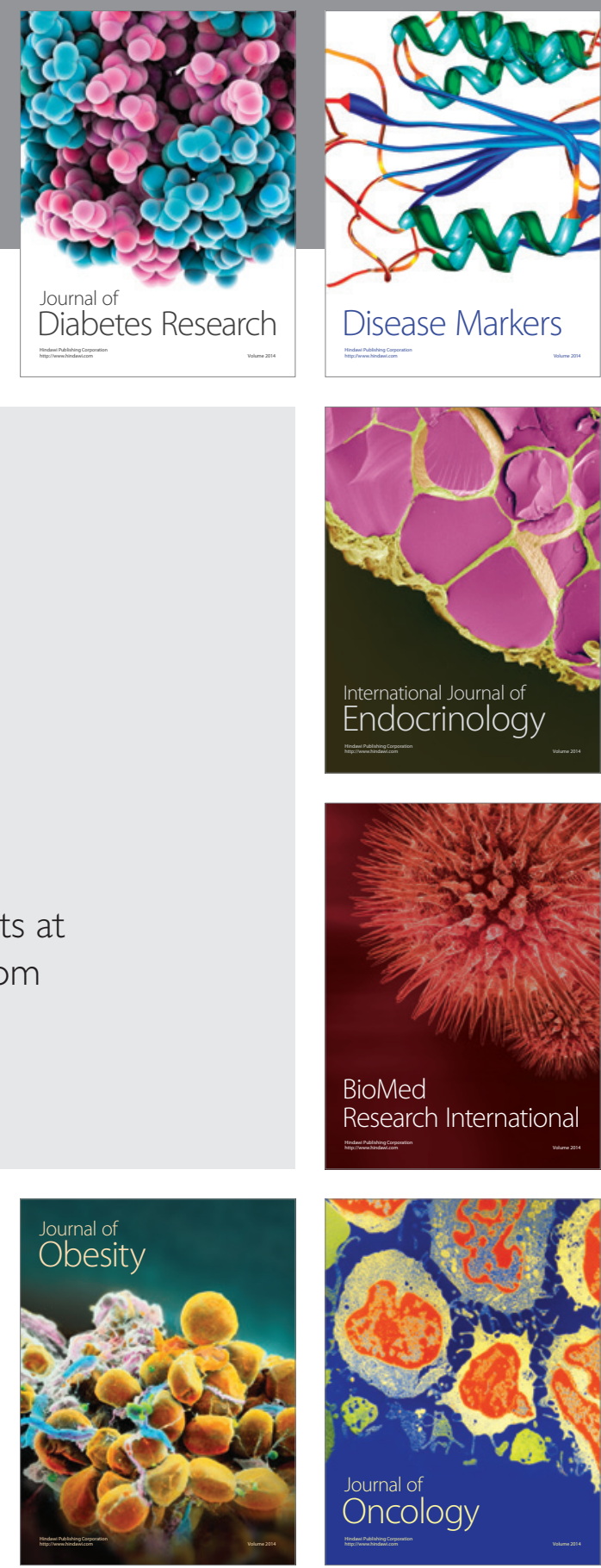

Disease Markers
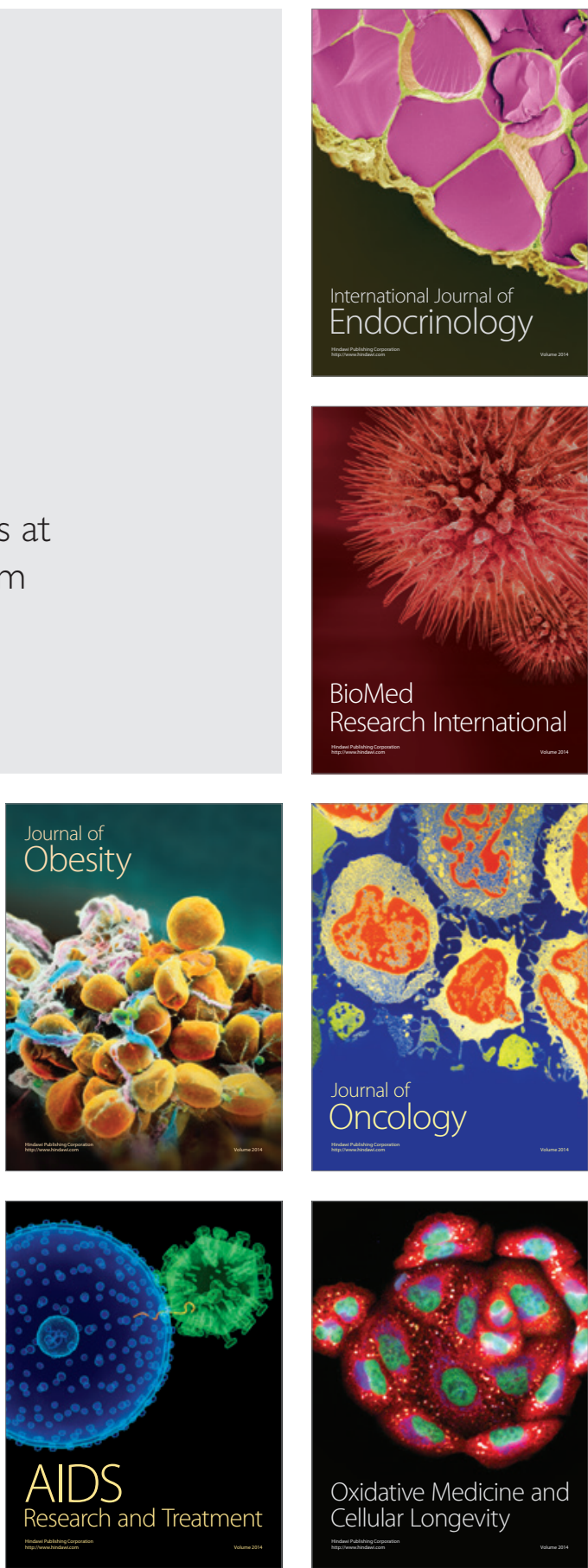